\title{
CONHCIMENTOS PROFISSIONAIS MOBILIZADOS POR PROFESSORES ENGENHEIROS PARA GERIR DILEMAS DA PRÁTICA PEDAGÓGICA
}

\author{
Jefferson da Silva Moreira ${ }^{1}$, Marinalva Lopes Ribeiro ${ }^{2}$, \\ 1. Bolsista de Iniciação Científica PIBIC/CNPq, Graduando em Licenciatura em Pedagogia, Universidade Estadual de Feira \\ de Santana, e-mail: moreirajefferson92@yahoo.com.br \\ 2. Orientadora, Professora Plena do Departamento de Educação, Universidade Estadual de Feira de Santana, \\ e-mail: marinalva_biodanza@hotmail.com;
}

Palavras-chave: Docência universitária; Conhecimentos profissionais; Casos de Ensino; Formação de Professores.

\section{Introdução}

No Brasil, a docência no ensino superior têm se constituído, nos últimos dez anos, um terreno fértil para o desenvolvimento de problematizações no âmbito das pesquisas educacionais. Os diversos estudos produzidos sobre a temática convergem em denunciar uma problemática no que diz respeito a um conjunto de lacunas no âmbito dos conhecimentos profissionais de professores que atuam nesse nível de ensino, a saber: carência de discussões atinentes às dimensões epistemológicas e filosóficas relacionadas à educação e de natureza psicopedagógica (D’ÁVILA, 2013). Mobilizados por esse cenário de desafios, o texto em tela coloca em relevo resultados finais de pesquisa que objetivou compreender quais são os conhecimentos profissionais mobilizados por professores universitários que atuam em cursos de Engenharia de uma universidade pública baiana para gerir dilemas que se manifestam no cotidiano da sala de aula universitária. A questão de pesquisa que orientou o desenvolvimento desta investigação foi a seguinte: quais são os conhecimentos profissionais mobilizados por professores que atuam em cursos de Engenharia da Universidade Estadual de Feira de Santana (UEFS) para gerir dilemas que se manifestam no cotidiano do seu locus de atuação profissional?

O marco teórico da pesquisa funda-se em discussões tecidas por autores que se debruçam ao estudo da Pedagogia Universitária (D’ÁVILA, 2013; SOARES e CUNHA, 2010; entre outros), os quais denunciam, em suas pesquisas, a problemática em torno da carência de propostas de formação inicial e continuada para professores que atuam nesse nível de ensino. Ancoramo-nos, também, em estudos sobre a base de conhecimentos profissionais para a docência (SHULMAN, 2014; GAUTHIER, 2006) e casos de ensino enquanto instrumentos investigativos e formativos. O conceito de dilemas, proposto por Zabalza (2004, p. 61) que o define como "[...] todo um conjunto de situações bipolares ou multipolares que se apresenta ao professor no desenrolar da sua atividade profissional [...]", também foi adotado como referencial no nosso trabalho.

\section{Metodologia}

Este estudo está ancorado nos pressupostos da abordagem da pesquisa qualitativa, possuindo algumas características e especificidades próprias que a diferem, por exemplo, da pesquisa quantitativa. Dentre estas singularidades destacam-se: dados com um enfoque majoritariamente interpretativo, com a perspectiva de compreender as impressões e subjetividades dos sujeitos participantes (LÜDKE E ANDRÉ; 1986). O locus de coleta de dados da pesquisa foi o Departamento de Ciências Exatas (DEXA) e o Departamento de Ciência e Tecnologia (DTEC) da UEFS. No primeiro momento da pesquisa, foi encaminhado para o e-mail de cinquenta (50) professores lotados nos departamentos supracitados um questionário socioprofissional, com questões abertas e fechadas, buscando levantar o perfil 
profissional desses sujeitos. Do total de quinze questionários enviados, tivemos o retorno de, apenas, quatro. Os dados obtidos por meio do referido instrumento de coleta de dados nos permitiu caracterizar esses sujeitos: possuem idades que variam entre 33 e 43 anos de idade. Três deles são do sexo feminino e um do sexo masculino. Todos possuem a titulação de mestres e/ou doutores, com uma experiência profissional que varia entre quatro e dezessete anos. Juntamente com o questionário supracitado, encaminhamos, via endereço eletrônico, o caso de ensino "O dilema de Ricardo", .

A produção acadêmica existente, atualmente, sobre casos de ensino indicam a possibilidade de sua utilização nos processos de formação de professores de diferentes níveis e modalidades de ensino. Um caso de ensino pode ser definido como "um documento descritivo de situações reais ou baseadas na realidade, elaborado especificamente para ser utilizado como ferramenta no ensino de professores" (NONO e MIZUKAMI, 2002, p. 72). O caso é criado para possibilitar a discussão, análise e interpretação sobre diversos acontecimentos da prática pedagógica. Eles revelam, ainda, circunstâncias das práticas dos professores, e, assim, os oferecem oportunidades para refletirem sobre situações cotidianas conflituosas. Para a análise dos dados valemo-nos da utilização da técnica de análise de conteúdo. De acordo com Bardin (2011 apud Santos 2012) esta pode ser definida como um "conjunto de instrumentos de cunho metodológico em constante aperfeiçoamento, que se aplicam a discursos (conteúdos e continentes) extremamente diversificados". Na análise de Bardin (1977), essa técnica caracteriza-se por três etapas: a) a pré-análise, b) exploração do material, c) tratamento dos resultados, inferência e interpretação.

\section{Resultados e discussão}

Ao analisarem o caso de ensino supracitado, os professores participantes da nossa pesquisa foram estimulados a relatarem quais são os conhecimentos profissionais da docência mobilizados para gerir situações conflituosas do cotidiano da prática pedagógica. A professora Priscila destacou como conhecimento profissional imprescindível para o exercício do magistério no Ensino Superior, o domínio do conhecimento específico da matéria e a necessidade de relacioná-lo ao cotidiano da profissão. Ao apontar a necessidade de que exista uma integração entre as diversas disciplinas do curso, a docente aponta princípios do que atualmente se discute sobre a interdisciplinaridade:

Ter o conhecimento dos conteúdos relacionados às disciplinas que ministra. Além disso, associá-los com a profissão e com outras disciplinas do curso, saber apontar onde os estudantes aplicarão aqueles conhecimentos quando no exercício da profissão (Priscila).

Para Shulman (2014), o conhecimento da área específica se constitui um elemento fulcral para que a docência possa ser exercida com qualidade em qualquer nível e modalidade de ensino, possibilitando, consequentemente, a aprendizagem dos estudantes. No entanto, gostaríamos de destacar que o conhecimento específico da matéria, por si só, é incipiente na garantia de uma aprendizagem significativa. Acreditamos, assim, que se torna indispensável que o professor universitário tenha consciência dos elementos da Didática, da Psicologia da aprendizagem, das concepções teóricas e epistemológicas dos processos de avaliação, além da organização de planejamento e estratégias de ensino que possibilitem aos alunos serem protagonistas nas suas aprendizagens.

\footnotetext{
${ }^{1} \mathrm{O}$ material relata as experiências de um professor formado em Engenharia Naval, cuja aproximação com a docência no ensino superior deu-se pela influência da pesquisa. No referido caso de ensino, o professor Ricardo relata suas experiências na condução de atividades de ensino que considerou exitosas e outras que avaliou como fracassadas.
} 
Outro aspecto destacado por Priscila é a importância da experiência profissional no campo da Engenharia: "A experiência profissional (conhecimento mais prático) em campo também é importante. Sinto certa dificuldade em algumas disciplinas por não estar atuando como Engenheira no mercado de trabalho, o que dificulta expor aos alunos o que é ou não prática na indústria (Priscila)." Sem sombras de dúvidas, o conhecimento da experiência, o saber tácito, adquirido no exercício da profissão, possui relevância para os formadores de profissionais desenvolverem um trabalho que atenda às especificidades que o cotidiano exige. Outro elemento sinalizado por dois dos sujeitos da nossa pesquisa como conhecimentos profissionais indispensáveis para o exercício da docência universitária é a capacidade de o professor lançar mão de planejamento e estratégias didáticas de acordo com o objetivo que pretende alcançar, além de favorecer atividades que primem pelo desenvolvimento da autonomia dos estudantes:

[...] o professor precisa conhecer e lançar mão de diferentes abordagens didáticas, pois, muitas vezes, o problema vem do excesso de dirigismo que os professores usam para procurar cumprir o programa de um componente curricular. Sair do dirigismo implica em construir percursos não tão controlados, o que é bom, mas também gera dúvidas nos próprios professores sobre suas habilidades de gerenciar novas situações (Ricardo).

O depoimento de Ricardo está em consonância com as contribuições teóricas de Shulman, ao destacar os processos de raciocínio pedagógico que são mobilizados pelos professores ao transformarem o conhecimento específico das suas disciplinas em ensino. Mizukami et. al. (2010) nos advertem para o fato de que o raciocínio pedagógico "consiste em técnica de raciocínio e ação, abrangendo seis aspectos comuns ao ato de ensinar: compreensão, transformação, instrução, avaliação, reflexão e nova compreensão". Destacam, ainda, que é por meio desse processo que os conhecimentos profissionais da docência são construídos.

A professora Angélica sinaliza a importância do desenvolvimento de planejamentos visando o alcance dos objetivos, embora reconheça a necessidade formativa para planejar situações de ensino que possibilitem a aprendizagem dos estudantes. De fato, o planejamento da prática pedagógica possui um papel vital nos mais diversos níveis e modalidades de ensino. Para Abreu e Masetto (1990), possui um papel fundante na concretização de estratégias que visem desenvolver capacidades cognitivas superiores nesses sujeitos.

Por fim, mas não menos importante, destacamos as colocações de Ricardo sobre a necessidade de um conhecimento para tratar das questões éticas que envolvem a profissão de Engenharia e o fazer acadêmico, aspectos que já foram discutidos anteriormente, mas que nos convocam a dialogar com Freire (1996, p. 16) quando destaca que o ensino exige, de modo sine qua non, uma dimensão ética para o seu exercício: "não é possível pensar os seres humanos longe, sequer, da ética, quanto mais fora dela. Estar longe ou pior, fora da ética, entre nós, mulheres e homens é uma transgressão".

\section{Considerações finais}

O presente trabalho teve por objetivo geral investigar, nas representações de professores universitários que atuam em cursos de engenharia da Universidade Estadual de Feira de Santana (UEFS), quais são os conhecimentos profissionais mobilizados por 
professores universitários da área de Engenharia para gerir dilemas que se manifestam no cotidiano do seu locus de atuação profissional.

Os achados empíricos da pesquisa permite-nos afirmar que os professores colaboradores vivenciam dilemas de diversas naturezas no âmbito universitário. Dentre eles, destacam-se os relacionados à fragilidade no domínio de conteúdo específico, didático e pedagógico para o exercício da docência no Ensino Superior. Ao analisarem o caso de ensino "O dilema de Ricardo" os professores revelaram como dilemas vivenciados no âmbito universitário, o fato de nem sempre se prepararem adequadamente para as aulas e de terem de lidar com o plágio feito pelos seus alunos.

Desse modo, consideramos urgente a necessidade de criação de propostas de profissionalização para esses profissionais, buscando incentivar uma cultura que prime pela construção da profissionalidade da categoria, isto é, um conjunto de conhecimentos, saberes, destrezas e atitudes próprias dessa profissão.

\section{Referências}

ABREU, M. C; MASETTO, M. T. O professor universitário em aula. 8. ed. São Paulo: Autores Associados, 1990.

ALMEIDA, L. R. M. Avaliação da aprendizagem: reflexões sobre os desafios atuais. In: RIBEIRO, M.; MARTINS, E.; CRUZ, A. (Orgs.). Docência no ensino superior: desafios da prática educativa. Salvador: EDUFBA, 2011.

D`ÁVILA, C. Profissão docente na educação superior. Curitiba, PR: CRV, 2013.

FREIRE, Paulo. Pedagogia da autonomia: Saberes necessários à prática educativa. São Paulo: Paz e Terra, 1996.

GAUTHIER, C. Por uma teoria da pedagogia: pesquisas contemporâneas sobre o saber docente. trad. Francisco Pereira. 2. ed. ijuí: ed. unijuí, 2006.

LÜDKE, M.; ANDRÉ, M. E. D. A. Pesquisa em educação: abordagens qualitativas. São Paulo: EPU, 1986.

MIZUKAMI, M. da G. N. et. al. Escola e aprendizagem da docência: processos de investigação e formação. São Carlos: EDUFScar, 2010.

MIZUKAMI, M. G. N. Aprendizagem da docência: algumas contribuições teóricas de L. S. Shulman.

NONO, M. A.; MIZUKAMI, M. G. Casos de ensino e processos de aprendizagem profissional docente. R. bras. Est. pedag., Brasília, v. 83, n. 203/204/205, p. 72-84, jan./dez. 2002.

SHULMAN, L. Conhecimento e ensino: fundamentos para a nova reforma. Cadernoscenpec. São Paulo. v.4. n.2. p.196-229. Dez. 2014.

SOARES, S. R; CUNHA, M. I. Formação do professor: a docência universitária em busca de legitimidade. EDUFBa: Salvador, 2010.

ZABALZA, M. Diários de aula: contributo para o estudo dos dilemas práticos dos professores. Portugal. Porto Editora, LDA, 2004. 